\title{
Reframing Information Literacy as Academic Cultural Capital: A Critical and Equity-Based Foundation for Practice, Assessment, and Scholarship
}

\section{Amanda L. Folk}

\begin{abstract}
Within the past decade, academic librarianship has increased its focus on critical librarianship and assessing student success, as well as undergoing a complete reconceptualization of information literacy. However, our assessment and scholarship related to information literacy and student success largely neglects the persistent racial and social-class achievement gaps in American higher education. This article draws upon a critical social theory commonly used in higher education research-cultural capital - to consider the ways in which information literacy as threshold concepts may enable or constrain success for students whose identities higher education has traditionally marginalized. Finally, Estela Mara Bensimon's equity cognitive frame is introduced to consider the ways in which we can ground our practice, assessment, and scholarship in our professional values of equity and inclusion.
\end{abstract}

Within the past decade, the Association of College \& Research Libraries (ACRL) has released several significant documents, each having substantial implications for our professional practice. In 2010, ACRL published The Value of Academic Libraries: A Comprehensive Research Review and Report, which calls upon academic librarians to assess their practice, particularly in terms of student success, to articulate explicitly the value they add to their institutions. ${ }^{1}$ The release of this publication has resulted in a flurry of assessment activity, as well as ACRL-sponsored initiatives like the Assessment in Action program. ${ }^{2}$ The recently released follow-up report, $A c a-$ demic Library Impact: Improving Practice and Essential Areas to Research, reaffirms and updates the student success agenda initially established in the Value report. ${ }^{3}$ Within the same time period, ACRL completely reconceptualized information literacy through the articulation of threshold concepts, dispositions, and knowledge practices in the Framework for Information Literacy for Higher Education, an acknowledgment of the complex and sociocultural nature of information literacy. ${ }^{4}$ Despite the increasing prominence of critical librarianship, particularly as it relates to information literacy instruction, and the heightened visibility of diversity and inclusion in higher education in the Impact report, academic librarianship lacks a critical approach to student success in higher education rooted in an equity framework.

* Amanda L. Folk is Assistant Professor and Head, Teaching \& Learning at The Ohio State University, University Libraries Teaching E Learning Department, email: folk.68@osu.edu library.osu.edu. @2019 Amanda Folk. 
The release of these three significant documents provides an opportunity to reexamine and expand upon existing critical approaches to information literacy, student success, and academic librarianship. Whereas the discourse related to critical teaching praxis has remained primarily at the micro level (that is, its relationship to the information literacy instruction classroom), the student success agenda articulated in the Value and Impact reports requires us to consider the macro context as well (in other words, the higher education context in which information literacy and its related instructional interventions are situated). While the articulated goal of information literacy instruction is to help students develop critical, analytical, and reflective modes of thinking for the purpose of lifelong learning, we must acknowledge that we are teaching students to enact these modes of thinking in specific and immediate contexts and that students' performance in those contexts has direct implications for their academic outcomes.

Despite its focus on student success, the Value report largely neglects the persistent racial and social-class achievement gaps in higher education and the ways in which academic libraries may contribute to or ameliorate these gaps. The Impact report notably does include a discussion of diversity and inclusion as a current trend in higher education, but it does not provide a critical, equity-based framework for addressing persistent achievement gaps. Therefore, the Impact report is a useful starting point, but additional work is necessary to align the student success agenda with the profession's equity, diversity, and inclusion goals. ${ }^{5}$ In terms of information literacy, the shift from a task- or skills-based conceptualization of information literacy to one rooted in the articulation of threshold concepts, dispositions, and knowledge practices is positive. However, as a profession, we have neglected to consider the implications of this shift for critical librarianship with respect to these racial and social-class achievement gaps outside the information literacy instruction classroom. By ignoring these achievement gaps, we become complicit in the reproduction of inequitable outcomes for students whose identities higher education has traditionally marginalized.

Emily Drabinski and Scott Walter consider the implications of the value agenda: “Our field often stops at the articulation of general topic areas for potential research rather than doing the hard work of identifying critical questions that matter for the future of our work and its contributions to the campus, higher education, or society, more broadly." 6 With this paper, I intend to contribute to the identification of critical questions for the future of academic librarianship and to expansively frame our role as student success and teaching and learning partners using James Elmborg's seminal essay about critical information literacy ${ }^{7}$ as a foundation. To do this, I present evidence of the racial and social-class achievement gaps in higher education and discuss their absence from library and information science (LIS) scholarship. I then introduce a critical social theory commonly used in educational research to provide an equity-based foundation for a consideration of the ways in which academic librarians can approach our practice, assessment, and research in service of creating inclusive and equitable learning experiences that explicitly strive to address persistent racial and social-class achievement gaps.

\section{Racial and Social-Class Achievement Gaps}

Racial and social-class achievement gaps have been well documented in the higher education literature. According to the National Center for Education Statistics (NCES), the postsecondary enrollment rates of students of color have been steadily increasing since $1976 .{ }^{8}$ During that time period, Hispanic student enrollment rose from 4 to 17 percent and Asian/Pacific 
Islander student enrollment increased from 2 to 7 percent, and the enrollment of Black/ African-American students increased from 10 to 14 percent. However, enrollment rates for Black/African-Americans peaked at 15 percent in 2011. Despite these steady enrollment increases, a postsecondary racial achievement gap persists. A recent report from the National Student Clearinghouse Research Center reported degree completion rates disaggregated by race/ethnicity for a cohort of students who enrolled in a variety of postsecondary institution types in fall 2010. ${ }^{9}$ Overall, Asian/Asian-American and White students had the highest sixyear completion rates at 63 and 62 percent, respectively. Hispanic and Black/African-American students had the lowest six-year completion rates at 46 and 38 percent, respectively. ${ }^{10}$

The nebulous category of social class also has associated achievement gaps. Higher education research often uses first-generation status (in other words, students whose parents have not attained a college degree) as a proxy for social class or socioeconomic status (SES), since it can be easier to gain access to information about parental educational attainment than access to students' financial aid information (such as Pell Grant status). ${ }^{11}$ Research shows firstgeneration students are less likely to persist after both their first and second years of college and have lower four- and six-year completion rates than their continuing-generation peers. ${ }^{12}$ Jennifer Engle and Vincent Tinto found that only 66 percent of low-income first generation students persisted from their first to second year of college, and 11 percent completed a bachelor's degree within six years. ${ }^{13}$ However, 79 percent of higher-income, continuing-generation students persisted after their first year of college, and 55 percent completed a bachelor's degree within six years.

Clearly, a persistent and complicated problem plagues American higher education. These achievement gaps are significant, as the benefits of completing a bachelor's degree are not trivial, for both the individual student and for society. ${ }^{14}$ Although upward mobility (in other words, movement into a higher social class or higher income bracket) does not need to be an explicit goal for college enrollment, the potential for increased lifetime earnings and higher social status is a benefit of attaining a four-year college degree.$^{15} \mathrm{In}$ addition, higher levels of education tend to result in better health outcomes, as well as "hold[ing] jobs that offer greater sense of accomplishment [and] more independence and opportunities for creativity." 16 There is no singular cause of racial and social-class achievement gaps in American higher education. A variety of factors contributes to these gaps, including students' financial situations and family obligations. However, institutional and academic culture likely contribute to these achievement gaps as well, given higher education's deep historical connections with both White and upper-middle-class cultures. Students whose identities higher education has traditionally marginalized may face cultural barriers in higher education, which has implications for students' academic engagement and sense of belonging. ${ }^{17}$

Despite the prevalence of research addressing the relationship between academic outcomes and race/ethnicity and social class in the higher education literature, similar research is glaringly absent from the LIS literature, an omission that seems particularly striking in relation to scholarship about information literacy and student success. On the one hand, this is not terribly surprising, since librarianship is an overwhelmingly white profession. ${ }^{18}$ Perhaps this is one reason why, as a profession, we opt to speak generally about diversity and multiculturalism, reinforcing a general sentiment of "treating everyone nicely" that generates good feelings among [White] LIS practitioners, educators, and scholars, rather than addressing issues of power and privilege centered around Whiteness. ${ }^{19}$ Academic librarianship scholarship also 
has not paid much attention to social class or SES. This may be due to broader cultural issues, particularly in the United States, as many Americans tend to identify as middle class, because they regularly encounter people whose economic situations appear to be both better and worse than their own ${ }^{20}$ and the negative stigma of being associated with a lower social class. ${ }^{21}$

Indeed, Project Information Literacy, one of the most well-respected, large-scale studies of undergraduates students and information literacy, makes almost no mention of race/ethnicity and social class. ${ }^{22}$ Some data are disaggregated by institution type (that is, 2-year and 4-year institutions), which might provide basic insight into the relationship between information literacy, race/ethnicity, and social class, since students of color and lower-SES students are more likely to enroll in 2-year institutions, ${ }^{23}$ however, this is not made explicit. A few studies have examined library usage or research practices by race $^{24}$ and social class. ${ }^{25}$ The value of these studies is significant; however, the relationship(s) among information literacy, academic culture in higher education, student success, and either race/ethnicity or social class remains largely underexplored.

Despite the lack of engagement with race and social class in empirical research related to information literacy, Elmborg and others have addressed the sociocultural contexts in which information literacy is enacted. Elmborg asserts that critical information literacy views "schools as agents of culture and shapers of student consciousness." ${ }^{26}$ Students demonstrate their information literacy through literacy events, such as research assignments, situated within a specific cultural context, ${ }^{27}$ in which students must know "the codes used by the community and the customs and conventions in play" 28 and "non-conforming students are [viewed as] 'rejects."'29 Elmborg expands on this in a contemporaneous article that introduces Mary Louise Pratt's conceptualization of educational spaces as "contact zones," in which "cultures meet, clash, and grapple with each other, often in contexts of highly asymmetrical relations of power." 30

Others have made a similar argument, asserting that information literacy is often negotiated within epistemic or professional communities and that research must consider those collective or collaborative aspects of information literacy in practice. ${ }^{31}$ Collective and collaborative settings typically have inherent power structures. ${ }^{32}$ Existing literature about information literacy and critical pedagogy has often considered the power dynamic between the librarian as instructor and the students in the classroom; however, our profession has given less consideration to the broader sociocultural context in which information literacy is enacted and the implications of power in determining what constitutes legitimate participation or performance within academic culture. For example, instructors or faculty often create assignments, hold particular expectations for performance based on what they consider to be appropriate or legitimate, and subsequently assign a grade based on a student's ability to meet those expectations, which has a direct connection to students' academic outcomes (such as GPA, persistence, and degree completion).

This lack of engagement with both race and social class in information literacy scholarship requires us to question academic librarianship's commitment to equity, diversity, and inclusion. Estela Mara Bensimon argues that an equity approach to student learning and achievement requires scholars and practitioners to interrogate our practices and institutional cultures, both of which continue to reproduce inequitable outcomes for students of color and lower-SES students. ${ }^{33}$ This kind of interrogation makes the "invisible visible and undiscussable discussable." ${ }^{34}$ The absence of such an interrogation indicates our profession's complicity in the reproduction of these inequitable outcomes, since the invisibility of achievement gaps does 
not provide space for addressing them. Indeed, Drabinski and Walter charge the profession to consider which questions are worth asking, not only for our profession, but also for our institutions and the constituents we serve, such as students. ${ }^{35}$ In light of the student success agenda presented in both the Value and Impact reports, I argue that academic librarianship needs to expand upon the critical foundation that Elmborg provided by drawing upon a complementary critical social theory to conceptualize the role of information literacy in the postsecondary academic context - cultural capital. Bourdieusian theory is useful for unpacking Elmborg's arguments related to academic culture, power, and learning, as well as explicitly connecting information literacy to broader theoretical conceptions and empirical research related to student success in higher education.

\section{Cultural Capital and Educational Contexts}

Pierre Bourdieu's conceptualization of cultural capital ${ }^{36}$ is commonly used as a theoretical foundation for exploring the ways in which traditionally marginalized student populations navigate educational institutions and academic culture. Anne Goulding provides a concise overview of cultural capital, describing it as "a sociological concept linked to social inequality and social position, and is often described as a set of cultural competencies which a person needs to acquire to participate in a whole range of cultural activities." ${ }^{\prime 37}$ The theory of cultural capital asserts that cultural resources, such as clothing, language and/dialect, and educational attainment, enable or constrain social mobility within fields of production, or "structured space[s] in which the positions and their interrelations are determined by the distributions of different kinds of...capital." ${ }^{38}$ In other words, the cultural capital one brings to bear in navigating and participating in a particular sociocultural space determines one's position in it. An individual's habitus, a "set of socialized dispositions" ${ }^{39}$ or the "unconscious recognition of patterns, rules, and expectations based on one's social class, family history, gender, education, and interactions with others at all levels within society," largely informs their behavior in a particular field. ${ }^{40}$ However, many of the patterns, rules, and expectations for higher-status fields of production remain tacit (that is, as an unspoken set of expectations for participation) to individuals who have not cultivated the habitus of that particular sociocultural context, meaning that "outsiders in certain social situations are easily identified by missteps." ${ }^{41}$

Cultural capital has its roots within the conflict tradition of sociology, which views schools and other social institutions as fields of production that perpetuate inequality for students who have not cultivated the habitus of upper middle class, White, patriarchal, heteronormative culture valued in educational spaces..$^{42}$ Indeed, previous research indicates that students of different social classes and students of color have difficulty accumulating the privileged cultural capital and cultivating the necessary habitus to participate successfully in educational spaces, ${ }^{43}$ which implies that expectations for participation may remain tacit to these students. This results in two intersecting consequences in terms of social-class and racial achievement gaps. First, instructors may incorrectly consider students who do not cultivate the dominant habitus as "intellectually inferior" or "lack[ing] ability" through no fault of the student. ${ }^{44}$ Second, students may internalize instructors' dismissal or the frustration they feel when they attempt to participate in a cultural context in which the expectations remain tacit and subsequently question their belonging, resulting in feelings of alienation, imposterism, and isolation. ${ }^{45}$ 


\section{Information Literacy as Academic Cultural Capital}

The Framework arguably takes the sociocultural contexts in which information literacy is enacted into consideration. It articulates information literacy as a set of threshold concepts, each of which has associated knowledge practices and dispositions. One of the defining hallmarks of threshold concepts is that they are discursive. ${ }^{46}$ Jan H.F. Meyer and Ray Land assert that "specific discourses have developed within disciplines to represent (and simultaneously privilege) particular understanding and ways of seeing and thinking, ${ }^{\prime 47}$ and new members may encounter challenges engaging with or participating in these discourses. Information literacy, however, is a transdisciplinary concept that addresses discourse within academic culture writ large. As such, the discursive nature of information literacy threshold concepts, as well as their associated dispositions and knowledge practices, articulate the ways in which students are expected to think like emerging scholars. Thus these concepts serve as a form of cultural capital (in other words, cultural competencies) that allows students to successfully access the habitus (that is, set of internalized, socialized, and privileged dispositions) of academic culture. This influences the ways in which students will navigate the academic field of production (i.e. their courses) and how established members (that is to say, faculty) will respond to students' performance related to relevant situated practices (such as research assignments), either validating, questioning, or rejecting an individual student's participation in academic culture. Due to the transdisciplinary nature of information literacy, course instructors may not perceive the need to explicitly address and develop these privileged ways of thinking and acting, assuming that someone else is addressing or developing this cultural capital, or blind spots created by expertise may prevent them from perceiving that these ways of thinking must be addressed or developed at all. ${ }^{48}$ The modes of thinking articulated by the six information literacy threshold concepts may remain tacit to students who are not from the culture(s) that higher education tends to privilege. Hence, students who may not have developed these ways of thinking and acting like a scholar may be perceived as outsiders through no fault of their own.

Another defining characteristic of threshold concepts is that they are transformative. ${ }^{49}$ The Framework addresses the transformative nature of threshold concepts in terms of knowledge acquisition, alluding to the belief that crossing a conceptual threshold transforms the way in which the learner perceives phenomena within that disciplinary frame. However, Meyer and Land state that the transformation may go beyond that of disciplinary understanding, stating that "threshold concepts lead not only to transfigured thought but to a transfiguration of identity and adoption of an extended or elaborated discourse." ${ }^{50}$ This identity transformation has significant implications for student populations who have been traditionally marginalized in higher education, particularly when information literacy is viewed as a form of academic cultural capital.

Existing research indicates that first-generation students and/or students of color may feel that they are bridging two different cultures - their home culture and their academic culture ${ }^{51}$ Even though families may be supportive of these students in their educational pursuit, families may be less prepared for the practical ways in which college enrollment will change the role of the college student within the family. ${ }^{52}$ As students grapple with their identity transformations, they may feel as if they are "an imposter in one world [academic culture] and a traitor to the other [home culture]." ${ }^{33}$ The modes of thinking articulated in the information literacy threshold concepts may contribute to these feelings, as students are encouraged to 
question authority, interrogate their own beliefs in light of new perspectives that they may be encountering in college, and to cultivate their own authoritative voice. Indeed, in the current political climate in which information serves as a political commodity, some students or their families may view the modes of thinking related to information literacy as subversive. ${ }^{54}$

Meyer and Land acknowledge that crossing a conceptual threshold includes an affective component, one that may "be unsettling, involving a sense of loss" for the learner. ${ }^{55}$ Given the evidence that many marginalized student populations often experience challenges as they transition into and within college, as well as the understanding that the information literacy threshold concepts articulate the ways in which students will think like scholars, it is imperative that we take seriously the implications of the current conceptualization of information literacy for the student whose identities higher education has traditionally marginalized.

Some readers may be resistant to characterizing information literacy as a form of academic cultural capital, because cultural capital can be used to discuss the ways in which marginalized populations are excluded from particular cultures. However, this characterization can have positive implications. The reconceptualization of information literacy as a series of threshold concepts with associated dispositions and knowledge practices explicitly articulates modes of critical thinking that are privileged in academic culture that may have previously remained tacit. However, simply articulating these modes of thinking is not enough. When information literacy is treated as a form of academic cultural capital, it provides a new lens through which academic librarians can view our work, particularly those of us who are interested in critical librarianship and equity in teaching and learning.

\section{Starting with an Equity Frame}

The discussion and recommendations for practice, assessment, and scholarship that follow are guided by Bensimon's equity cognitive frame. ${ }^{56}$ Bensimon argues that instructors and institutional administrators should view achievement gaps as a result of a "learning problem of institutional actors...rather than as a learning problem of students." ${ }^{27}$ In other words, an equity cognitive frame requires course instructors and librarians to interrogate their pedagogy and teaching practice(s), and institutional academic culture more broadly, as potential barriers to student learning and success, rather than placing the burden solely on students and their perceived deficiencies (such as lack of motivation, lack of academic preparation, and other factors). Furthermore, an equity cognitive frame requires us to "focus on institutional practices and the production of unequal educational outcomes for minority group students," 58 which, as mentioned previously, has been lacking in scholarship related to information literacy and student success. As such, the following recommendations will attempt to balance the need for institutions to change their cultural practices to be more inclusive of diverse student populations with the need to help students to participate successfully in the current cultural practices of higher education to meet their educational attainment goals.

\section{Implications for Practice}

In this section, I will discuss the implications of viewing information literacy as a form of academic cultural capital for practice, particularly as it relates to academic librarians' roles as teaching and learning consultants, partners, or collaborators. Given the wealth of literature related to critical pedagogy in the information literacy instruction classroom, I focus specifi- 
cally on the ways in which academic librarians can work with course instructors to develop, revise, or scaffold assignments or courses to help all students develop their information literacy, paying particular attention to the ways in which we can focus on equitable learning for marginalized student populations. Academic librarians often serve as discourse mediators, because of what Michelle Holschuh Simmons calls "our unique position that allows mediation between the non-academic discourse of entering undergraduates and the specialized discourse of disciplinary faculty" due to being "simultaneously insiders and outsiders of the classroom and of the academic disciplines in which [we] specialize." ${ }^{59}$ I argue that this role of discourse mediator is more important than ever for critical librarianship, since the conceptualization of information literacy has shifted from focusing on specific tasks or skills to focusing on the modes of critical thinking that are valued and rewarded in academic culture.

In the following sections, I address the transformative and discursive nature of information literacy by offering complementary pedagogical approaches in which academic librarians can ground our work with course instructors as teaching and learning collaborators using an equity cognitive frame. Many readers may find that they are already doing this work. I argue that the profession has lacked a broader conceptual model and language in which to ground this work, one that is consistent with the conceptual models and language of our higher education colleagues.

\section{Addressing the Transformative Nature of Information Literacy through an Asset-Based Approach}

As addressed previously, crossing a conceptual threshold may involve an identity transformation, which may be particularly disruptive for marginalized student populations as they may feel that they are straddling two distinct cultural contexts. ${ }^{60}$ In addition, marginalized students report that their home identities are often not represented or valued in academic culture. ${ }^{61}$ Because of this, academic librarians should promote asset-based approaches to developing students' information literacy to our instructional colleagues, ${ }^{62}$ because inquiry-based activities and assignments are excellent opportunities to help students engage their cultural identities in their academic work. ${ }^{63}$ In general, asset-based approaches honor "the values and experiences students bring with them to college" and help instructors to combat deficit approaches to marginalized student populations. ${ }^{64}$

There are several asset-based approaches that may be used to guide our collaborative interactions with course instructors, such as Tara J. Yosso's concept of community cultural wealth. ${ }^{65}$ A similar asset-based approach that is gaining traction in higher education, particularly related to Latinx students, is "funds of knowledge." 66 Funds of knowledge has been applied to K-12 settings in the United States to educate Mexican and Mexican-American students for more than two decades, but it has only recently become more prominent in postsecondary education, in spite of evidence of its benefits in primary and secondary education. ${ }^{67}$ Research shows that drawing on students' funds of knowledge surfaces and validates the strengths that students with marginalized identities bring to education and their academic work, rather than continually focusing on their perceived weaknesses. ${ }^{68}$ In addition, this approach might influence students' motivation. ${ }^{69}$ Students report that their academic work becomes more meaningful when they have the opportunity to incorporate their identities, experiences, and interests, and there is evidence that this promotes learning that can be transferred to other contexts. ${ }^{70}$ 
I have argued elsewhere, drawing upon students' funds of knowledge for situated practices within academic culture (in other words, research assignments) can help students to develop their information literacy and integrate their home and academic identities, ${ }^{71}$ as it engages the important knowledge that students bring with them from their home cultures, their identities, and their lived experiences. As teaching and learning collaborators, academic librarians should consider ways in which we can encourage instructors to use inquiry-based assignments to honor and validate the identities, lived experiences, and prior knowledge that students from all backgrounds bring to their collegiate academic experience. $^{72}$

\section{Addressing the Discursive Nature of Information Literacy by Surfacing Blind Spots Created by Expertise}

Existing scholarship has indicated that blind spots created by instructors' expertise may make it difficult for them to design research assignments that are suitable for novices in the discipline $^{73}$ or to communicate effectively their expectations for performance on these assignments. ${ }^{74}$ In addition, instructors often struggle to articulate when and how students learn the modes of thinking related to information literacy and often perceive the barriers to meeting expectations for performance to be student-centered rather than reflecting on or interrogating the potential barriers that are instructor-created..$^{75}$

As teaching and learning collaborators, academic librarians should encourage and help course instructors to apply established pedagogical approaches that promote transparent teaching practices related to the development of information literacy. ${ }^{76}$ Two useful approaches are the Decoding the Disciplines model $(\mathrm{DtD})^{77}$ and the Transparency in Learning and Teaching in Higher Education (TILT Higher Ed) project at the University of Nevada, Las Vegas. Both DtD and TILT Higher Ed require instructors to consider the higher order modes of thinking that they expect students to develop and apply in their courses, as well as interrogating the ways in which faculty both model these modes of thinking and provide students with opportunities to practice them prior to submitting high-stakes assignments. DtD as a model has been linked specifically to helping students to cross conceptual portals and has been used as a model for initiating conversations with faculty about information literacy threshold concepts, ${ }^{78}$ as well as a model for equity-minded faculty development more generally. ${ }^{79}$ TILT Higher Ed has been used specifically "to focus on advancing underserved students' success in higher education." ${ }^{80}$ If information literacy is considered a form of academic cultural capital that may remain tacit, thus presenting barriers to success for some student populations, models that require faculty to interrogate blind spots created by their expertise are critical to creating equitable learning experiences. Librarians, as discourse mediators, teaching and learning collaborators, and information literacy experts, have a responsibility to initiate and facilitate this kind of work as it relates to the development of information literacy.

The interrogation of practices and expectations in service of transparency may also open the door for important conversations related to the role of legitimacy in academic and disciplinary discourse, including the legitimization of particular types of information sources or particular methods of communication. ${ }^{81}$ Not only can librarians use models like DtD and TILT Higher Ed in service of equitable and transparent learning experiences, but they might also be used to begin conversations about shifting academic and institutional cultures to be more inclusive. 


\section{Implications for Assessment and Scholarship}

The articulation of information literacy as academic cultural capital presents new opportunities for assessment, research, and scholarship, particularly related to critical librarianship and equitable learning experiences. Previous research about information literacy development has mostly neglected race and class, and it is likely that what we know about information literacy development and student success applies primarily to middle-class or upper-middleclass White students. On a positive note, the library value research agenda presented in the recently released Impact report does encourage librarians to consider "the effects of library instruction on success outcomes for diverse student populations" ${ }^{\prime 22}$ and acknowledges inclusivity as a trend in higher education that is gaining prominence in institutional mission statements. However, the research agenda articulated in the Impact report does not grapple with the ways in which academic libraries can work toward creating real cultural change in our institutions in the service of closing persistent social-class and racial achievement gaps. Therefore, as a profession, we need to take this a step further and establish theoretical and empirical foundations for doing this work. Academic librarians can demonstrate our value to our students, our teaching and learning partners, our institutions, and to higher education by focusing more broadly on the ways in which specific practices related to information literacy within academic culture enable or constrain the success of some student populations. Not only would this focus, first and foremost, help students to meet their personal educational attainment goals, it would also serve institutional goals to retain students through degree completion.

Future LIS research should intentionally seek to understand the ways in which marginalized student populations develop their information literacy, as well as their experiences with common situated practices (such as research assignments) and the development of their student-scholar identity. While some of this work may need to be comparative, such as understanding the differences between first-generation and continuing-generation students or students of color and White students, we should be careful not to create or reinforce a normative experience against which all other experiences are measured. For example, exploring Latinx students' experiences with research assignments in their first year of college at a predominantly White institution (PWI) is worthy of investigation in and of itself, and these experiences do not need to be compared to or measured against the experiences of their White peers to be valuable to our work in closing achievement gaps.

Given the transformative and discursive nature of threshold concepts, future research should draw upon the robust scholarship related to student identity development in higher education to explore the academic identity transformation(s) of students. Academic identity transformations may be particularly troublesome for students whose identities have been traditionally marginalized in higher education, since they may feel as if they have bifurcated identities that they are attempting to maintain or integrate. In addition, students may feel a sense of loss as they develop their student-scholar, scholarly, or professional identities, perhaps at the expense of their home identities. Situated practices in academic culture, such as research assignments, provide opportunities to explore the ways in which students grapple with these identity transformations, including whom they do or do not turn to for support as they participate in academic culture. ${ }^{83}$ This kind of exploration may surface the ways in which information literacy and related situated practices either engage or isolate some students as they work to meet their educational attainment goals. 
Future research should also consider a broader view of the value of academic librarians and focus on our role as teaching and learning consultants, partners, and collaborators, as well as exploring how these roles can be used to enable equitable learning experiences and instigate long-term cultural change in our institutions. For example, academic librarians may partner with academic programs or departments to investigate students' research assignment or course grades based on student demographic characteristics to determine if social-class or racial achievement gaps are evident. Librarians who employ pedagogical approaches DtD or TILT Higher Ed in their teaching and learning collaborations with instructors may want to undertake an investigation of student outcomes on a particular assignment or in the course pre- and post-revision. In addition, students enrolled in these courses could be interviewed to understand how their experiences with assignments or courses that employ DtD or TILT Higher Ed compared to their experiences in other courses. Librarians who have the opportunity to apply DtD or TILT Higher Ed with instructors in a more programmatic way (such as a multiday workshop, grant program, or inquiry group) may want to explore the ways in which that experience shaped the instructors' understanding of information literacy or their own teaching practices and how their practices enable or constrain student learning.

In summary, future research related to student success, information literacy, and academic libraries must be viewed "as the outcome of co-location and co-participation, where people shape and inform their practices (including information literacy practice) and operationalize information skills, in agreed upon ways." ${ }^{84}$ In particular, future scholarship in this area must acknowledge racial and social-class achievement gaps and consider the ways in which academic culture, as well as academic libraries' participation in academic culture, enables or constrains the reproduction of these gaps.

\section{Conclusion}

This essay should serve as a call to action for academic librarians, practitioner scholars, and LIS researchers. We can no longer neglect race and class in our practice or scholarship if our profession values equity, diversity, and inclusion. Ignorance or avoidance of achievement gaps will only serve to make them invisible, meaning that we are complicit in the reproduction of these gaps. In addition, academic librarians must engage with scholarship that helps us to understand the broader higher education context in which we are situated if we are serious about narrowing and closing persistent social-class and racial achievement gaps in higher education. Reframing information literacy as threshold concepts provides the opportunity to reconsider our teaching and learning practices and collaborations, as the Framework articulates the privileged modes of critical thinking related to information use and knowledge creation in higher education. However, the articulation of these privileged modes of thinking is not enough. Librarians must consider the cultural context in which these modes of thinking are valued and enacted, including the situated practices in which students must demonstrate them, and consider the ways in which these situated practices may alienate or isolate particular student populations. We must continue to approach our own information literacy teaching practices with a critical lens, but we must also seek ways to make change in the broader cultural context. Many academic librarians are already doing this work, but, as a profession, we must make this role more explicit and provide common conceptual foundations and language to discuss this work. 
Those of us who take a critical approach to our practice may find the idea of a student success agenda to be completely unfavorable, as it can serve to reinforce a neoliberal agenda in our institutions. ${ }^{85}$ We should continue to critique this agenda, but we must also find agency to enable equitable outcomes among students enrolled in our institutions and produce evidence of these equitable outcomes, not simply to prove our value to our institutions but to increase our value to our students. We must recognize the value of a college education, including its relationship to economic and overall well-being, and the burden of debt that accompanies students who are not able to complete the degree they started. We do not have to buy into a neoliberal, functionalist approach to education to be concerned about equity in academic outcomes and student success.

\section{Notes}

1. Association of College \& Research Libraries, Value of Academic Libraries: A Comprehensive Research Review and Report, researched by Megan Oakleaf (Chicago, IL: Association of College \& Research Libraries, 2010), available online at www.acrl.ala.org/value/?page_id=21 [accessed 21 May 2019].

2. For an overview of the Assessment in Action program, as well as access to program summaries and reports, visit www.ala.org/acrl/AiA [accessed 21 May 2019].

3. Lynn Silipigni Connaway, William Harvey, Vanessa Kitzie, and Stephanie Mikitish, Academic Library Impact: Improving Practice and Essential Areas to Research (Chicago, IL: Association of College \& Research Libraries, 2017), available online at www.ala.org/acrl/sites/ala.org.acrl/files/content/publications/whitepapers/academiclib. pdf [accessed 21 May 2019].

4. Association of College \& Research Libraries, The Framework for Information Literacy for Higher Education, available online at www.ala.org/acrl/standards/ilframework [accessed 21 May 2019].

5. ACRL Board of Directors, "ACRL Board to Establish New Equity, Diversity, and Inclusion Initiative," ACRL Insider (Mar. 5, 2018), available online at https://www.acrl.ala.org/acrlinsider/archives/15380 [accessed 21 May 2019].

6. Emily Drabinski and Scott Walter, "Asking Questions That Matter," College E Research Libraries 77, no. 3 (2016): 264-68, 265.

7. James Elmborg, “Critical Information Literacy: Implications for Instructional Practice," Journal of Academic Librarianship 32, no. 2 (2006): 192-99.

8. National Center for Education Statistics, Digest of Education Statistics, 2016 (Washington, DC: U.S. Department of Education, 2018), available online at https://nces.ed.gov/programs/digest/d16/index.asp [accessed 21 May 2019].

9. Doug Shapiro et al., Completing College: A National View of Student Attainment Rates by Race and Ethnicity, Signature 12 Supplement, Fall 2010 Cohort (Herndon, VA: National Student Clearinghouse Research Center, 2017), available online at https://www.luminafoundation.org/files/resources/signature12-raceethnicity.pdf [accessed 21 May 2019].

10. These enrollment and degree completion rates simplify the reality, particularly for Asian/Asian-American and Hispanic/Latinx students, with some ethnic subgroups demonstrating higher levels of postsecondary access and achievement than others. See Lauren Musu-Gillete, Jennifer Robinson, Joel McFarland, Angelina KewalRamani, Anlan Zhang, and Sidney Wilkinson-Flicker, Status and Trends in the Education of Racial and Ethnic Groups 2016 (Washington, DC: U.S. Department of Education, National Center for Education Statistics, 2016), available online at https://nces.ed.gov/pubs2016/2016007.pdf [accessed 21 May 2019].

11. For example, the publication that coined the phrase "social-class achievement gap" focused on firstgeneration college students. See Nicole M. Stephens, MarYam G. Hamedani, and Mesmin Destin, "Closing the Social-Class Achievement Gap: A Difference-Education Intervention Improves First-Generation Students' Academic Performance and All Students' College Transition," Psychological Science 25, no. 4 (2014): 943-53.

12. Emily Forest Cataldi, Christopher T. Bennett, and Xianglei Chen, First-Generation Students: College Access, Persistence, and Postbachelor's Outcomes (Washington, DC: U.S. Department of Education, National Center for Education Statistics, 2018), available online at https://nces.ed.gov/pubs2018/2018421.pdf [accessed 21 May 2019]; Linda DeAngelo, Ray Franke, Sylvia Hurtado, John H. Pryor, and Serge Tran, Completing College: Assessing Graduation Rates at Four-Year Institutions (Los Angeles, CA: University of California at Los Angeles, Higher Education Research Institute, 2011), available online at https://heri.ucla.edu/DARCU/CompletingCollege2011.pdf [accessed 
21 May 2019]; Terry T. Ishitani, "Studying Attrition and Degree Completion Behavior among First-Generation College Students in the United States," Journal of Higher Education 77, no. 5 (2006): 861-85.

13. Jennifer Engle and Vincent Tinto, Moving beyond Access: College Success for Low-Income, First-Generation Students (Washington, DC: The Pell Institute for the Study of Opportunity in Higher Education, 2008), available online at https://files.eric.ed.gov/fulltext/ED504448.pdf [accessed 21 May 2019].

14. Michael Hout, "Social and Economic Returns to College Education in the United States," Annual Review of Sociology 38, no. 1 (2012): 379-400.

15. Philip Oreopoulos and Uros Petronijevic, "Making College Worth It: A Review of the Returns to Higher Education," The Future of Children 23, no. 1 (2013): 41-65.

16. Oreopoulos and Petronijevic, "Making College Worth It," 55.

17. Rashne R. Jehangir, Higher Education and First-Generation Students: Cultivating Community, Voice, and Place for the New Majority (New York, NY: Palgrave Macmillan, 2010); Sarah J. Mann, "Alternative Perspectives on the Student Experience: Alienation and Engagement," Studies in Higher Education 26, no. 1 (2001): 7-19; Stephen John Quaye, Kimberly A. Griffin, and Samuel D. Museus, "Engaging Students of Color," in Student Engagement in Higher Education: Theoretical Perspectives and Practical Approaches for Diverse Populations, 2nd ed., eds. Stephen John Quaye and Shaun R. Harper (New York, NY: Routledge, 2015), 15-35.

18. Chris Bourg, "The Unbearable Whiteness of Librarianship," Feral Librarian (blog, Mar. 3, 2014), available online at https://chrisbourg.wordpress.com/2014/03/03/the-unbearable-whiteness-of-librarianship/ [accessed 21 May 2019]; Todd Honma, "Trippin' Over the Color Line: The Invisibility of Race in Library and Information Studies," InterActions: UCLA Journal of Education and Information Studies 1, no. 2 (2005), n.p., retrieved from https:// escholarship.org/uc/item/4nj0w1mp [accessed May 21, 2019].

19. Christine Pawley, “Unequal Legacies: Race and Multiculturalism in the LIS Curriculum,” Library Quarterly 76, no. 2 (2006): 149-68, 162.

20. MaryBeth Walpole, "Economically and Educationally Challenged Students in Higher Education: Access to Outcomes," ASHE Higher Education Report 33, no. 3 (2007): 1-113.

21. Krista M. Soria, Welcoming Blue-Collar Scholars into the Ivory Tower: Developing Class-Conscious Strategies for Student Success (Columbia, SC: University of South Carolina, National Resource Center for the First-Year Experience and Students in Transition, 2015).

22. To view more information about Project Information Literacy and access their publications, visit http:// www.projectinfolit.org/ [accessed 21 May 2019].

23. Young Invincibles, Race and Ethnicity as a Barrier to Opportunity: A Blueprint for Higher Education Equity (2017), available online at http://younginvincibles.org/wp-content/uploads/2017/05/Higher-Education-Equity.pdf [accessed 21 May 2019].

24. Denice Adkins and Lisa Hussey, "The Library Lives of Latino College Students," Library Quarterly 76, no. 4 (2006): 456-80; David Green, "Supporting the Academic Success of Hispanic Students," in College Libraries and Student Culture: What We Know Now, eds. Lynda M. Duke and Andrew D. Asher (Chicago, IL: American Library Association, 2012), 87-108; Patricia Katapol, “Information Anxiety, Information Behavior, and Minority Graduate Students," Education Libraries 32, nos. 1/2 (2012): 5-14; Barbara MacAdam and Darlene P. Nichols, "Peer Information Counseling: An Academic Library Program for Minority Students," Journal of Academic Librarianship 15, no. 4 (1989): 204-09; Jeffrey M. Mortimore and Amanda Wall, "Motivating African-American Students through Information Literacy Instruction: Exploring the Link between Encouragement and Academic Self-Concept," Reference Librarian 50, no. 1 (2009): 29-42; Ethelene Whitmire, "Racial Differences in the Academic Library Experiences of Undergraduate Students," Journal of Academic Librarianship 25, no. 1 (1999): 33-37; Ethelene Whitmire, "Cultural Diversity and Undergraduates Academic Library Use," Journal of Academic Librarianship 29, no. 3 (2003): 148-61; Ethelene Whitmire, "The Campus Racial Climate and Undergraduates Perceptions of the Academic Library," portal: Libraries and the Academy 4, no. 3 (2004): 363-78; Ethelene Whitmire, "African American Undergraduates and the University Academic Library," Journal of Negro Education 75, no. 1 (2006): 60-66.

25. Firouzeh Logan and Elizabeth Pickard, "First-Generation College Students: A Sketch of Their Research Process," in College Libraries and Student Culture: What We Know Now, eds. Lynda M. Duke and Andrew D. Asher (Chicago, IL: American Library Association, 2012), 109-25; Elizabeth Pickard and Firouzeh Logan, "The Research Process and the Library: First-Generation College Seniors vs. Freshmen," College E Research Libraries 74, no. 4 (2013): 399-415; Krista M. Soria, Shane Nackerud, and Kate Peterson, "Socioeconomic Indicators Associated with First-Year College Students' Use of Academic Libraries," Journal of Academic Librarianship 41, no. 5 (2015): 636-43.

26. Elmborg, "Critical Information Literacy: Implications for Instructional Practice," 193.

27. Karen Nicholson makes a similar argument, asserting that we need to consider information literacy as a situated practice (that is to say, a set of competencies applied within a sociocultural context) within the neoliberal higher education context. Karen Nicholson, "Information Literacy as a Situated Practice in the Neoliberal 


\section{Reframing Information Literacy as Academic Cultural Capital 671}

University," Proceedings of the Annual Conference of the Canadian Association for Information Science (2014), available online at https://journals.library.ualberta.ca/ojs.cais-acsi.ca/index.php/cais-asci/article/view/864 [accessed 21 May 2019].

28. Elmborg, “Critical Information Literacy: Implications for Instructional Practice," 195.

29. Elmborg, "Critical Information Literacy: Implications for Instructional Practice," 194.

30. James Elmborg, "Libraries in the Contact Zone: On the Creation of Educational Space," Reference E User Services Quarterly 46, no. 1 (2006b): 56-64; Mary Louise Pratt, "Arts of the Contact Zone," in Professing the Contact Zone, ed. Janice M. Wolff (Urbana, IL: NCTE, 2005), 1-18, 4.

31. Kimmo Tuominen, Reijo Savolainen, and Talja Sanna, "Information Literacy as a Sociotechnical Practice," Library Quarterly 75, no. 3 (2005): 329-45; Annemaree Lloyd, "Information Literacy as a Socially Enacted Practice: Sensitising Themes for an Emerging Perspective of People-In-Practice," Journal of Documentation 68, no. 6 (2012): $772-83$.

32. Jonathan Cope, "Information Literacy and Social Power," in Critical Library Instruction, eds. Maria T. Accardi, Emily Drabinski, and Alana Kumbier (Duluth, MN: Library Juice Press, 2010), 13-27.

33. Estela Mara Bensimon, "Closing the Achievement Gap in Higher Education: An Organizational Learning Perspective," New Directions for Higher Education 131 (2005): 99-111.

34. Bensimon, "Closing the Achievement Gap in Higher Education," 99.

35. Drabinski and Walter, "Asking Questions That Matter."

36. Pierre Bourdieu, Outline of a Theory of Practice (Cambridge, UK: Cambridge University Press, 1977); Pierre Bourdieu, Distinction: A Social Critique of the Judgement of Taste (London, UK: Routledge, 1984); Pierre Bourdieu, "The Forms of Capital," in Handbook of Theory and Research for the Sociology of Education, ed. John George Richardson (New York, NY: Greenwood Press, 1986), 241-58; Pierre Bourdieu, Language and Symbolic Power (Cambridge, MA: Harvard University Press, 1991); Pierre Bourdieu, The Field of Cultural Production (New York, NY: Columbia University Press, 1993).

37. Anne Goulding, "Libraries and Cultural Capital," Journal of Librarianship and Information Science 40, no. 1 (2008): 235-37, 235.

38. Pierre Bourdieu, Language and Symbolic Power (Cambridge, MA: Harvard University Press), 14, as cited in Lisa Hussey, "Social Capital, Symbolic Violence, and Fields of Cultural Production: Pierre Bourdieu and Library and Information Science," in Critical Theory for Library and Information Science: Exploring the Social from Across the Disciplines, eds. Gloria J. Leckie, Lisa M. Given, and John E. Buschman (Santa Barbara, CA: ABC-CLIO), 41-51, 45.

39. Penny Jane Burke, The Right to Higher Education: Beyond Widening Participation (New York, NY: Routledge, 2012), 40.

40. Hussey, "Social Capital, Symbolic Violence, and Fields of Cultural Production," 43.

41. Hussey, "Social Capital, Symbolic Violence, and Fields of Cultural Production," 44.

42. Christopher J. Hurn, The Limits and Possibilities of Schooling: An Introduction to the Sociology of Education, 3rd ed. (Boston, MA: Allyn and Bacon, 1993).

43. Burke, The Right to Higher Education; Peter J. Collier and David L Morgan, "Is That Paper Really Due Today?": Differences in First-Generation and Traditional College Students' Understandings of Faculty Expectations," Higher Education 55, no. 4 (2008): 425-46; Lisa D. Delpit, "The Silenced Dialogue: Power and Pedagogy in Educating Other People's Children," Harvard Educational Review 58, no. 3 (1988): 280-98; Penelope Eckert, Jocks and Burnouts: Social Categories and Identity in the High School (New York, NY: Teachers College Press, 1989); Annette Lareau, Unequal Childhoods: Class, Race, and Family Life, 2nd ed. (Los Angeles: University of California Press, 2011).

44. Burke, The Right to Higher Education, 193.

45. Elmborg, "Libraries in the Contact Zone"; Jehangir, Higher Education and First-Generation Students; Mann, "Alternative Perspectives on the Student Experience."

46. Jan H.F. Meyer and Ray Land, "Threshold Concepts and Troublesome Knowledge: An Introduction," in Overcoming Barriers to Student Understanding: Threshold Concepts and Troublesome Knowledge, eds. Jan H.F. Meyer and Ray Land (New York, NY: Routledge, 2006), 3-18.

47. Meyer and Land, "Threshold Concepts and Troublesome Knowledge: An Introduction," 14.

48. Gloria J. Leckie, "Desperately Seeking Citations: Uncovering Faculty Assumptions about the Undergraduate Research Process," Journal of Academic Librarianship 22, no. 3 (1996): 201-08; Laura Saunders, "Faculty Perspectives on Information Literacy as Student Learning Outcomes," Journal of Academic Librarianship 38, no. 4 (2012): 226-36; Michelle Holschuh Simmons, "Librarians as Disciplinary Discourse Mediators: Using Genre Theory to Move Toward Critical Information Literacy," portal: Libraries and the Academy 5, no. 3 (2005): 297-311.

49. Meyer and Land, "Threshold Concepts and Troublesome Knowledge: An Introduction." 
50. Jan H.F. Meyer and Ray Land, "Threshold Concepts and Troublesome Knowledge: Issues of Liminality," in Overcoming Barriers to Student Understanding: Threshold Concepts and Troublesome Knowledge, eds. Jan H.F. Meyer and Ray Land (New York, NY: Routledge, 2006), 19-32, 21.

51. Howard B. London, "Breaking Away: A Study of First-Generation College Students and Their Families," American Journal of Education 97, no. 2 (1989): 144-70; Jehangir, Higher Education and First-Generation Students.

52. London, "Breaking Away."

53. Jehangir, Higher Education and First-Generation Students, 42.

54. Geoff Walton, "Information Literacy Is a Subversive Activity: Developing a Research-Based Theory of Information Discernment," Journal of Information Literacy 11, no. 1 (2017): 137-55.

55. Meyer and Land, "Threshold Concepts and Troublesome Knowledge: An Introduction," 16.

56. Bensimon, "Closing the Achievement Gap in Higher Education."

57. Bensimon, "Closing the Achievement Gap in Higher Education," 100.

58. Bensimon, "Closing the Achievement Gap in Higher Education," 103.

59. Simmons, "Librarians as Disciplinary Discourse Mediators," 298.

60. Elmborg, "Libraries in the Contact Zone," 56; Jehangir, Higher Education and First-Generation Students.

61. Jehangir, Higher Education and First-Generation Students.

62. Sonja Ardoin, "Helping Poor- and Working-Class Students Create Their Own Sense of Belonging," New Directions for Student Services 162 (2018): 75-86; Georgianna L. Martin, Matthew J. Smith, and Brittany M. Williams, "Reframing Deficit Thinking on Social Class," New Directions for Student Services 162 (2018): 87-93.

63. Amanda L. Folk, "Drawing on Students' Funds of Knowledge: Using Identity and Lived Experience to Join the Conversation in Research Assignments," Journal of Information Literacy 12, no. 2 (2018), 44-59.

64. Martin, Smith, and Williams, "Reframing Deficit Thinking on Social Class," 87.

65. Tara J. Yosso, "Whose Culture Has Capital? A Critical Race Theory Discussion of Community Cultural Wealth," Race Ethnicity and Education 8, no. 1 (2005): 69-91. For example, Kyzyl Fenno-Smith, Kim Morrison, Gr Keer, and Jeffra Bussmann, "Who Knows? A Cultural Wealth Approach to Knowledge Production, Information Literacy and Civic Participation," ACRL 2015 "Creating Sustainable Community" Portland, Oregon, March $25-28,2015$.

66. Luis C. Moll, Cathy Amanti, Deborah Neff, and Norma Gonzalez, "Funds of Knowledge for Teaching: Using a Qualitative Approach to Connect Homes and Classrooms," Theory into Practice 31, no. 2 (1992): 132-41; Carlos G. Vélez-Ibáñez and James B. Greenberg, "Formation and Transformation of Funds of Knowledge among U.S.-Mexican Households," Anthropology \& Education Quarterly 23, no. 4 (1992): 313-35; Cecilia Rios-Aguilar and Judy Marquez Kiyama, "Funds of Knowledge: An Approach to Studying Latina(o) Students' Transition to College," Journal of Latinos Education 11 (2012): 2-16; Funds of Knowledge in Higher Education: Honoring Students' Cultural Experiences and Resources as Strengths, eds. Judy Marquez Kiyama and Cecilia Rios-Aguilar (New York, NY: Routledge, 2017).

67. Kiyama and Rios-Aguilar, Funds of Knowledge.

68. Amanda M. Carpenter and Edlyn Vallejo Peña, "Self-Authorship among First-Generation Undergraduate Students: A Qualitative Study of Experiences and Catalysts," Journal of Diversity in Higher Education 10, no. 1 (2017): 86-100; Milagros Castillo-Montoya, "Deepening Understanding of Prior Knowledge: What Diverse First-Generation College Students in the U.S. Can Teach Us," Teaching in Higher Education 22, no. 5 (2017): 587-603; Folk, "Drawing on Students' Funds of Knowledge."

69. Folk, "Drawing on Students' Funds of Knowledge"; Amanda L. Folk, "Learning the Rules of Engagement: Exploring First-Generation Students' Academic Experiences through Academic Research Assignments" (PhD diss., University of Pittsburgh, 2018), http://d-scholarship.pitt.edu/35132/ [accessed May 21, 2019].; Susan A. Ambrose, Michael W. Bridges, Michele DiPietro, Marsha C. Lovett, and Marie K. Norman, How Learning Works: Seven Research-Based Principles for Smart Teaching (San Francisco, CA: Jossey-Bass, 2010).

70. Michele Eodice, Anne Ellen Geller, and Neal Lerner, The Meaningful Writing Project: Learning, Teaching, and Writing in Higher Education (Logan, UT: Utah State University Press, 2016).

71. Folk, "Drawing on Students' Funds of Knowledge."

72. At the 7th Biennial Threshold Concepts Conference in June 2018, Yvonne Nalani Meulemans spoke about an activity that the librarians at California State University at San Marcos, a Hispanic-serving institution (HSI) and an Asian American Native American Pacific Islander Serving Institution (AANAPISI), use to help students develop their student-scholar identity and begin to cross the "Scholarship as Conversation" threshold. The librarians ask students to reflect on the discourse communities to which they already belong to facilitate a discussion about the academic discourse community that they are now joining as student-scholars. Based on Stephen Brookfield's "Letter to Successors" in the book Becoming a Critically Reflective Teacher, the students are then asked to "offer advice on how the next group of students can interact with the content," including a reflec- 
tion on "how they proceeded through the research process, their lessons learned, and advice on how to do well in research endeavors." This is an excellent example of how students' funds of knowledge can be incorporated into their academic work, as well as addressing the ways in which their home and academic identities are not necessarily mutually exclusive. Yvonne Nalani Meulemans, "Super Friends: Leveraging Complementary Yet Discordant Powers of Threshold Concepts and Assessment to Engage Faculty in Reflective Teaching," 7th Biennial Threshold Concepts Conference (2018), available online at https://thresholdconceptsconference.wordpress. com/a-sessions/ [accessed 15 September 2018]; Allison Carr, email message to the author, July 27, 2018.

73. Leckie, "Desperately Seeking Citations."

74. Barbara Valentine, "The Legitimate Effort in Research Papers: Student Commitment Versus Faculty Expectations," Journal of Academic Librarianship 27, no. 2 (2001): 107-15.

75. Barbara Alvarez and Nora Dimmock, "Faculty Expectations of Student Research," in Studying Students: The Undergraduate Research Project at the University of Rochester, eds. Nancy Fried Foster and Susan Gibbons (Chicago, IL: Association of College \& Research Libraries, 2007), 1-6; Michael J. Carlozzi, “They Found It-Now Do They Bother? An Analysis of First-Year Synthesis," College \& Research Libraries, 79, no. 5 (2018): 659-70; Jonathan Cope and Jesús E. Sanabria, "Do We Speak the Same Language? A Study of Faculty Perceptions of Information Literacy," portal: Libraries and the Academy 14, no. 4 (2014): 475-501; Eleanor Dubicki, "Faculty Perceptions of Students' Information Literacy Skills Competencies," Journal of Information Literacy 7, no. 2 (2013), 97-125; Saunders, "Faculty Perspectives on Information Literacy."

76. Mary-Ann Winkelmes et al., "A Teaching Intervention That Increases Underserved College Students' Success," Peer Review 18, no. 1/2 (2016), available online at https://www.aacu.org/peerreview/2016/winter-spring/ Winkelmes [accessed 21 May 2019]; Office of the Executive Vice President and Provost, University of Nevada, Las Vegas (UNLV), "Transparency in Learning and Teaching in Higher Education," available online at https:// www.unlv.edu/provost/teachingandlearning [accessed 6 July 2018].

77. Joan Middendorf and David Pace, "Decoding the Disciplines: A Model for Helping Students to Learn Disciplinary Ways of Thinking," New Directions for Higher Education, no. 98 (Summer 2004): 1-12; Joan Middendorf and David Pace, "Decoding the Disciplines: Improving Student Learning," available online at http:// decodingthedisciplines.org/ [accessed 6 July 2018].

78. Joan Middendorf and Laura Cruz, "Decoding the Disciplines: Bring Your Favorite Threshold Concept and We Will Decode It (Uncover the Underlying Expert Mental Moves)," 7th Biennial Threshold Concepts Conference (2018), available online at https://thresholdconceptsconference.wordpress.com/workshops/ [accessed 21 May 2019]; Sara D. Miller, “Diving Deep: Reflective Questions for Identifying Tacit Disciplinary Information Literacy Knowledge Practices, Dispositions, and Values through the ACRL Framework for Information Literacy," Journal of Academic Librarianship 44, no. 3 (2018): 412-18.

79. Kimberly A. Costino, “Equity-Minded Faculty Development: An Intersectional Identity-Conscious Community of Practice Model for Faculty Learning," Metropolitan Universities 29, no. 1 (2018): 117-36.

80. UNLV, "Transparency in Learning and Teaching in Higher Education."

81. Geoff Walton's discussion of Foucault's discourse analysis informed the assertion that I am making here. He asserts that discourse analysis "reveals the potential for re-constituting IL (both at the learner and theoretical level) as an approach to critiquing academic discourse which enables students to become participants in its discursive practice rather than simply conforming to it." If DtD and TILT Higher Ed are used to interrogate expectations related to discursive practices, then we may be able to use them to begin more complex and potentially difficult conversations with instructors related to power, privilege, and legitimacy in our institutions or in our disciplines. Walton, "Information Literacy Is a Subversive Activity," 146-47.

82. Connway et al., Academic Library Impact, 6.

83. Folk, "Learning the Rules of Engagement".

84. Lloyd, "Information Literacy as a Socially Enacted Practice," 780.

85. Cathy Eisenhower and Dolsy Smith, "The Library as 'Stuck Place': Critical Pedagogy in the Corporate University," in Critical Library Instruction: Theories and Methods, eds. Maria T. Accardi, Emily Drabinski, and Alan Kumbier (Sacramento, CA: Library Juice Press, 2010), 305-17; Nicholson, "Information Literacy as a Situated Practice in the Neoliberal University"; Geoff Walton and Jamie Cleland, "Information Literacy: Empowerment or Reproduction in Practice? A Discourse Analysis Approach," Journal of Documentation 73, no. 4 (2017): 582-94. 